\title{
Maternal nutrition, inadequate gestational weight gain and birth weight: results from a prospective birth cohort
}

Anke Diemert ${ }^{*}$, Susanne Lezius ${ }^{2}$, Mirja Pagenkemper ${ }^{1}$, Gudula Hansen ${ }^{1}$, Alina Drozdowska ${ }^{1}$, Kurt Hecher ${ }^{1}$, Petra Arck $^{1+}$ and Birgit C. Zyriax ${ }^{3+}$

\begin{abstract}
Background: The aim of our study was to examine maternal weight gain as well as nutrient intake in pregnancy throughout each trimester compared to current recommendations in a low-risk population and its correlation to birth weight. Additionally, we have investigated the association of maternal nutrition with gestational weight gain and birth weight in an economically unrestricted population.
\end{abstract}

Methods: Our analysis was carried out in a population-based prospective birth cohort in Hamburg, Germany. 200 pregnant women and 197 infants born at term were included in the analysis. Maternal body weight, weight gain throughout gestation, and birth weight, macro- and micronutrients were assessed based on a $24 \mathrm{~h}$ dietary recall in each trimester. Our main outcome measures were weight gain, birth weight, and self-reported dietary intake in each trimester in comparison to current recommendations.

Results: One third of the women were characterized by an elevated pre-pregnancy BMl, $60 \%$ did not comply with current weight gain recommendations. Particularly overweight and obese women gained more weight than recommended. In a multivariate analysis birth weight correlated significantly with maternal BMI $(p=0.020)$, total weight gain $(p=0.020)$ and gestational week $(p<0.001)$. Compared to guidelines mean percentage of energy derived from fat $(p=0.002)$ and protein $(p<0.001)$ was significantly higher, whereas carbohydrate $(p=0.033)$ intake was lower. Mean fiber intake was significantly lower $(p<0.001)$. Saturated fat and sugar contributed largely to energy consumption. Gestational weight gain correlated significantly with energy $(p=0.027)$, carbohydrates $(p=0.008)$, monosaccharides and saccharose $(p=0.006)$ intake. $98 \%$ of the pregnant women were below the iodine recommendation, while none of the women reached the required folate, vitamin $D$, and iron intake.

Conclusions: During gestation appropriate individual advice as to nutrient intake and weight gain seems to be of high priority. Pregnancy should be used as a 'window of opportunity' for behavioral changes.

Keywords: Pregnancy, Gestational weight gain, Birth cohort, Diet, Nutrient intake, Overweight, Obesity

\section{Background}

An increased body-mass-index (BMI) at the beginning of pregnancy and inadequate gestational weight gain (GWG) represent a substantial health burden for mother and child. Normal weight for women at childbearing age should be strived for. However, the global obesity

\footnotetext{
* Correspondence: a.diemert@uke.de

${ }^{\dagger}$ Equal contributors

${ }^{1}$ Department of Obstetrics and Fetal Medicine, University Medical Center

Hamburg-Eppendorf, Martinistrasse 52, Hamburg 20246, Germany

Full list of author information is available at the end of the article
}

epidemic has resulted in an increasing number of overweight and obese women entering pregnancy. Data from cross-sectional studies indicate that at present about $20 \%$ of the German women aged 20-39 are overweight, another $9-14 \%$ are obese and up to $18 \%$ are affected by central obesity $[1,2]$. In addition a substantial proportion of pregnant women seems to be characterized by an inadequate GWG according to the recommendations of the US Institute of Medicine (IOM) [3, 4]. Both extremes, excessive or inadequate GWG can lead to adverse pregnancy outcomes. Maternal complications 
arising from excessive GWG include an increased rate of caesarean section, hypertensive disorders, diabetes, weight retention and abdominal adiposity. The latter conditions determine a women's lifetime risk for cardiovascular disease [5-11]. Fetal risks includes stillbirth, miscarriage, malformation, macrosomia, as well as an increased risk of premature death and transgenerational obesity [12-17].

Adherence to a balanced diet throughout pregnancy, influences maternal body weight as well as short- and long-term health of mother and child [18-20]. Data of the 'German National Nutrition Survey II' indicate, that average nutrient intake in women of childbearing age is at least in parts inadequate [21]. During gestation the need for certain micronutrients increases more than energy requirement [22]. Thus, deficiencies in micronutrients may occur frequently, leading to adverse outcomes for mother and child. However, information as to dietary intake throughout gestation is limited [23, 24]. Most birth cohorts did not evaluate maternal dietary habits. Nutritional data for pregnant women derive mainly from cross-sectional studies where pregnant women represent a minority. Furthermore, in previous studies nutrient intake was measured only once during pregnancy. Considering the fact that pregnancy constitutes a unique opportunity to change dietary behavior in order to preserve maternal and fetal health more research on this topic is warranted.

The aim of this paper was therefore to evaluate maternal weight gain and nutrient intake throughout pregnancy in an economically unrestricted prospective birth cohort comprising mostly normal pregnancies and to compare the nutrient intake to current guidelines and birth weight. Additionally, we have investigated the association of maternal nutrition with gestational weight gain and birth weight.

\section{Methods}

\section{Design and Recruitment}

From 2011-2013 200 healthy low risk women aged 18 years and older with singleton spontaneously conceived pregnancies presented at the University medical Centre Hamburg-Eppendorf to participate in this study between gestational age $12+0$ to $14+6$ weeks. Exclusion criteria were risk factors according to menstrual- (such as unknown last menstrual period), obstetrical- (such as history of IUGR or preeclampsia) and medical history (other diseases), drug usage (such as alcohol or tobacco) or chronic medication.

At 3 time points (once per trimester (gestational week $12+0$ to $14+6,22+0$ to $24+6$ and $34+0$ to $36+6$ ) participants presented for a detailed fetal ultrasound examination, psychometric and lifestyle questionnaires (24 hours-recall) and maternal blood draw. Additionally a morphology scan was performed at gestational week 20-24 and birth weight and pregnancy outcome was collected. Sociodemographic data such as familial status and education were also reported to ensure no constraints regarding dietary options.

\section{Data collection}

\section{Assessment of anthropometric data}

The maternal height and weight - light clothing, but no shoes allowed - were measured to the nearest $0.5 \mathrm{~cm}$ or $0.1 \mathrm{~kg}$ respectively, and taken with the same instruments (scale and yardstick) that were calibrated in regular intervals for the whole population at each visit. The body mass index (BMI) was calculated as $\mathrm{BMI}=$ weight $(\mathrm{kg}) /$ height $(\mathrm{m})^{2}$.

Pregnancy weight gain was compared with current S3 guideline on gestational diabetes derivated from the recommendation of the US Institute of Medicine (IOM), depending on BMI classes: 12.5-18 kg for underweight women, 11.5-16 kg for normal weight women, 7$11.5 \mathrm{~kg}$ for overweight women and 5-9 $\mathrm{kg}$ for obese women $[25,26]$.

\section{Nutritional counseling and assessment of nutrition}

Pregnant women included in our study were counseled on guideline recommended nutrition during pregnancy by physicians certified for nutritional medicine. Information about nutrition was obtained by using a 24 h dietary recall in each trimester based on the nutritional software EBISpro System based on the national food composition table (BLS 3.01). Recommendations for dietary intake of energy, macro- and micronutrients during pregnancy were based on the D-A-CH reference value of the German, Swiss and Austrian society for nutrition [22].

\section{Data analysis/Statistical methods}

Continuous variables are presented as means ( \pm standard deviations). Categorical variables are presented as absolute numbers and rates. Mean nutrition values are derived by patient-individual averaging.

Comparisons to guidelines or recommendations are performed using the one-sample $t$-test.

Time trends were determined with random effects models allowing for autoregression with a random intercept for the individual patients and adjusted for education level und maternal age. Associations with maternal weight gain and birth weight were analyzed using ANOVA models adjusted for maternal age, maternal BMI at the beginning of pregnancy, education level and in case of birth weight additionally for gestational week. Further adjustments are stated separately.

Not normally distributed parameters were log transformed where necessary. All analyses were two-sided 
with $\alpha=0.05$. No alpha adjustment for multiple testing was applied.

All calculations are performed using SPSS Version 21 (SPSS Inc., Cary, NC, USA).

\section{Results}

\section{Baseline characteristics}

Baseline characteristics of the study population are listed in Table 1. All women were married or living in a stable relationship. The study population consisted of 191 Caucasian, seven Asian, one African and one Latin American women. $78 \%$ of the participants

Table 1 Baseline characteristics of the PRINCE birth cohort. Depicted is either the mean value or the percentage value. Values are given as mean \pm 1 standard deviation (SD) or as absolute and relative frequencies $\left({ }^{a} n=197,{ }^{b} n=196\right)$

\begin{tabular}{|c|c|}
\hline Characteristics & Total $n=200$ \\
\hline \multicolumn{2}{|l|}{ Clinical characteristics } \\
\hline Maternal age (years) & $31.0( \pm 3.5)$ \\
\hline Height (cm) & $168( \pm 6)^{a}$ \\
\hline \multicolumn{2}{|l|}{ Weight } \\
\hline Weight at the beginning of pregnancy (kg) & $69.9( \pm 13.9)^{\mathrm{a}}$ \\
\hline BMI $\left(\mathrm{kg} / \mathrm{m}^{2}\right)$ & $24.7(4.6)^{a}$ \\
\hline $\mathrm{BMI}<18,5\left(\mathrm{~kg} / \mathrm{m}^{2}\right)$ & $4 \%(n=8)$ \\
\hline BMI $18,5-<25\left(\mathrm{~kg} / \mathrm{m}^{2}\right)$ & $63 \%(n=124)$ \\
\hline BMI $25-<30\left(\mathrm{~kg} / \mathrm{m}^{2}\right)$ & $21 \%(n=41)$ \\
\hline $\mathrm{BMI} \geq 30\left(\mathrm{~kg} / \mathrm{m}^{2}\right)$ & $12 \%(n=24)$ \\
\hline \multicolumn{2}{|l|}{ Parity } \\
\hline First pregnancy & $57 \%(n=114)$ \\
\hline Former pregnancy & $43 \%(n=86)$ \\
\hline 1 living child & $49 \%(n=41)$ \\
\hline$\geq 2$ living children & $13 \%(n=11)$ \\
\hline \multicolumn{2}{|l|}{ Delivery } \\
\hline Gestational age at delivery (weeks) & $40.0( \pm 1.5)^{\mathrm{a}}$ \\
\hline Fetal weight at delivery ( $\mathrm{g}$ ) & $3457( \pm 497)^{\mathrm{b}}$ \\
\hline$<3$ rd percentile & $2 \%(n=3)$ \\
\hline$>97$ th percentile & $2 \%(n=4)$ \\
\hline Life birth & 197 (98\%) \\
\hline Pregnancy discontinued (termination, miscarriage) & $3(2 \%)$ \\
\hline \multicolumn{2}{|l|}{ Lifestyle characteristics } \\
\hline \multicolumn{2}{|l|}{ Education level $^{\mathrm{b}}$} \\
\hline No high school diploma & $22 \%(n=44)$ \\
\hline High school or vocational diploma & $34 \%(n=66)$ \\
\hline College or higher education & $44 \%(n=86)$ \\
\hline \multicolumn{2}{|l|}{ Smoking habits } \\
\hline Current non-smokers & $100 \%$ \\
\hline \multicolumn{2}{|l|}{ Alcohol use } \\
\hline Alcohol abstinence & $100 \%$ \\
\hline
\end{tabular}

had a high educational level and two-thirds a normal weight at the beginning of pregnancy. One third were overweight (defined as BMI $>=25$ but lower than 30) or obese (defined as BMI $>=30$ ). $57 \%$ of study subjects were primipara.

\section{Energy and macronutrient intake}

During gestation the average daily energy intake in our study population increased from $1987 \mathrm{kcal}( \pm 505)$ in the first trimester to $2068 \mathrm{kcal}( \pm 463)$ in the second and $2151 \mathrm{kcal}( \pm 472)$ in the last trimester $(p=0.001$ for increase between first and 3rd trimester). Protein intake increased significantly from $76 \mathrm{~g}( \pm 24)$ in the first trimester to $80 \mathrm{~g}( \pm 21)$ in the second $(p=0.037)$ and $82 \mathrm{~g}$ $( \pm 23)$ in the third trimester $(p=0.003$ for increase between first and 3rd trimester). Major sources for protein were animal products (data not shown). With regard to the fat consumption daily intake increased significantly from $77 \mathrm{~g}( \pm 29)$ to $82 \mathrm{~g}( \pm 27)$ and $86 \mathrm{~g}( \pm 28)$ over the trimesters $(p=0.003$ for increase between first and 3rd trimester). Saturated fatty acids (SAFA) contributed mainly to mean total fat consumption (SAFA $=36 \mathrm{~g} \pm 10$ of total fat $81 \mathrm{~g} \pm 19$ ), whereas the intake of monounsaturated fatty acids $(26 \mathrm{~g} \pm 7)$ and polyunsaturated fatty acids (13 $\mathrm{g} \pm 4$ ) was much lower. Mean intake of docosahexaenoic acid (DHA), derivated from marine sources was $221 \mathrm{mg}( \pm 243)$. Throughout gestation carbohydrate intake raised from $239 \mathrm{~g}( \pm 65)$ in the first trimester to $245 \mathrm{~g}( \pm 66)$ in the 2nd trimester to $254 \mathrm{~g}( \pm 66)$ in the last trimester non-significantly $(p=0.152)$. Monosaccharide and saccharose contributed largely to the carbohydrate consumption (43\%), while mean fiber intake was low $(24 \mathrm{~g} \pm 6)$. When additionally adjusted for total energy no significant changes in macronutrient intake throughout pregnancy were observed.

If macronutrient intake was calculated in percentage of energy intake this was $16 \%$ from protein, $36 \%$ from fat, and $49 \%$ from carbohydrates. In comparison to current recommendations the overall mean protein and fat intake of the participants was significantly higher than recommended (protein 16 vs. $15 \%, p<0.001$ and fat 36 vs. $35 \%$, $p=0.002$ ). In addition, the percentage of saturated fat intake with regard to total fat consumption was much higher than recommended ( $45 \%$ vs. $10 \%, p<0.001$ ), whereas mean carbohydrate intake was significantly lower than recommended (49 vs. $50 \%, p=0.033$ ) (DACH Referenzwerte, 2015).

When categories instead of mean values were taken into account $38 \%$ of the pregnant women reported a protein intake below the recommended $15 \%$ of energy intake. Within the study population $58 \%$ of the pregnant women reported a fat intake above the upper threshold of $35 \%$ of energy predominately characterized by a high consumption of saturated fat, while $62 \%$ of 
the women did not fulfill the criteria of a sufficient intake of docosahexaenoic acid. As to carbohydrate intake $56 \%$ of the women were below the recommendation of $50 \%$ of energy. The percentage of women consuming less than $30 \mathrm{~g}$ fiber per day was $84 \%$. In each trimester mean dietary intake of protein, fat, carbohydrates and fiber differed significantly from the recommendation with the exception of fat and carbohydrate intake during the first trimenon.

\section{Micronutrient intake}

Mean intake of vitamins and minerals from food increased slightly between the first and the last trimester (Table 2). However, most changes were not significant, particularly when additionally adjusted for energy intake (data not shown). In each trimester mean dietary intake of certain micronutrients differ significantly from the recommendation (Table 2).

\section{Vitamins}

Compared to current recommendations mean dietary intake of vitamin $A, E, B_{1}, B_{2}$, and $B_{12}$ seems to be adequate (Table 2) [22]. However, on the average a considerable amount of the women did not reach the recommendation on vitamin $\mathrm{A}$ (37 \%), vitamin $\mathrm{E}(55 \%)$, vitamin $\mathrm{B}_{1}(48 \%)$, vitamin $\mathrm{B}_{2}(28 \%)$ and vitamin $\mathrm{B}_{12}$ (73\%) intake (Fig. 1). In addition $23 \%$ of the pregnant women did not reach the recommended intake of vitamin $C$, while $67 \%$ reported an insufficient intake of vitamin $B_{6}$ (Fig. 1). With regard to folate and vitamin $\mathrm{D}$ mean daily intake from food was much lower than recommended (folate $288 \mu \mathrm{g}( \pm 126)$ vs $550 \mu \mathrm{g}, p<0.001$; vitamin D $2.6 \mu \mathrm{g}( \pm 3.6)$ vs $20 \mu \mathrm{g}, p<0.001)$ (Table 2$)$. (DACH Referenzwerte, 2015). None of the pregnant women fulfilled on average the recommendation as to folate or vitamin D intake (Fig. 1).

\section{Minerals}

An iron requirement of $30 \mathrm{mg}$ throughout pregnancy is recommended, whereas mean daily iron intake in the study population was only $12 \mathrm{mg}( \pm 2 p<0.001)$ (Table 2) (DACH Referenzwerte, 2015). Thus, in $100 \%$ of the pregnant women iron supply in each trimester was inadequate (Fig. 1). For iodine the mean daily intake was $123 \mu \mathrm{g}( \pm 48)$ which is significantly less than the recommendation of $230 \mu \mathrm{g}(p<0.001)$ (Table 2) (DACH Referenzwerte, 2015). On the average $98 \%$ of the women were below the recommended threshold (Fig. 1).

Mean daily intake of calcium, magnesium and zinc seems to be adequate in comparison to the recommendation (calcium $1179 \mathrm{mg}( \pm 324)$ vs $1000 \mathrm{mg}$; magnesium $378 \mathrm{mg}( \pm 76)$ vs $310 \mathrm{mg}$, zinc $11 \mathrm{mg}( \pm 2)$ vs $10 \mathrm{mg}$ ). However, as to calcium, $32 \%$ of the pregnant women ingested less than recommended, while $18 \%$ of the women were below the recommendation of magnesium and $26 \%$ below the recommended zinc intake (Fig. 1).

Besides the intake of micronutrients from food, $96 \%$ $(n=192)$ of the women reported to use supplements. However, evaluation of the obtained data is difficult as various products were reported and most supplements were not used continuously (data not published).

Table 2 Intake of micronutrients during pregnancy compared with current recommendations (DACH Referenzwerte, 2015) [22]. Values are given as mean \pm 1 standard deviation (SD)

\begin{tabular}{|c|c|c|c|c|c|c|}
\hline Critical-micronutrients & 1. trimenon & 2. trimenon & 3. trimenon & mean intake & recommendation & $p$-value \\
\hline Iron (mg) & $12 \pm 4$ & $13 \pm 3$ & $12 \pm 3$ & $12 \pm 2$ & 30 & $<0.001$ \\
\hline lodine ( $\mu \mathrm{g})$ & $115 \pm 62$ & $130 \pm 86$ & $123 \pm 67$ & $123 \pm 48$ & 230 & $<0.001$ \\
\hline Vit D $(\mu \mathrm{g})$ & $2.5 \pm 3.7$ & $2.4 \pm 2.3$ & $2.8 \pm 4.4$ & $2.6 \pm 2.1$ & 20 & $<0.001$ \\
\hline Folat $(\mu \mathrm{g})$ & $273 \pm 124$ & $291 \pm 119$ & $296 \pm 133$ & $287 \pm 81$ & 550 & $<0.001$ \\
\hline \multicolumn{7}{|l|}{-Other-micronutrients } \\
\hline Vit A (mg) & $1.4 \pm 1.7$ & $1.7 \pm 1.5$ & $1.5 \pm 1.4$ & $1.5 \pm 0.9$ & 1.1 & $<0.001$ \\
\hline Vit E (mg) & $13 \pm 7$ & $14 \pm 7$ & $14 \pm 8$ & $13.5 \pm 5.0$ & 13 & n.s. \\
\hline Vit B1 (mg) & $1.3 \pm 0.5$ & $1.4 \pm 0.6$ & $1.4 \pm 0.6$ & $1.3 \pm 0.4$ & 1.3 & n.s. \\
\hline Vit B2 (mg) & $1.5 \pm 0.7$ & $1.7 \pm 0.6$ & $1.8 \pm 0.7$ & $1.7 \pm 0.4$ & 1.4 & $<0.001$ \\
\hline Vit B6 (mg) & $1.7 \pm 0.7$ & $1.8 \pm 0.7$ & $1.9 \pm 0.8$ & $1.8 \pm 0.5$ & 1.9 & 0.002 \\
\hline Vit B12 $(\mu \mathrm{g})$ & $4.7 \pm 4.7$ & $4.6 \pm 2.3$ & $4.9 \pm 2.7$ & $4.7 \pm 2.2$ & 3.5 & $<0.001$ \\
\hline Vit C (mg) & $146 \pm 90$ & $158 \pm 94$ & $166 \pm 105$ & $158 \pm 67$ & 105 & $<0.001$ \\
\hline Calcium (mg) & $1133 \pm 487$ & $1193 \pm 457$ & $1227 \pm 502$ & $1179 \pm 324$ & 1000 & $<0.001$ \\
\hline Magnesium (mg) & $359 \pm 103$ & $388 \pm 99$ & $386 \pm 106$ & $378 \pm 76$ & 310 & $<0.001$ \\
\hline Zinc (mg) & $11 \pm 4$ & $12 \pm 3$ & $11 \pm 3$ & $11 \pm 2$ & 10 & $<0.001$ \\
\hline
\end{tabular}




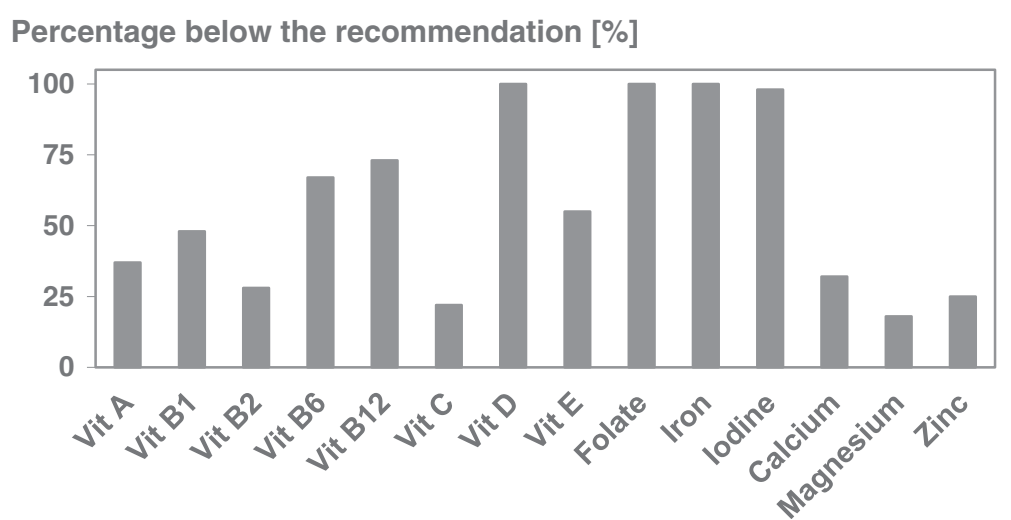

Fig. 1 Percentage of women below the recommended dietary intake of vitamins and minerals (DACH Referenzwerte, 2015) [22]

\section{Maternal BMI and gestational weight gain}

Mean maternal BMI at the beginning of pregnancy was $24.7( \pm 4.6)$, with $63 \%$ of the women being normal weight, $4 \%$ being underweight, $21 \%$ overweight and $12 \%$ obese at this time. In the second trimester maternal weight reached a BMI of $26.7( \pm 4.6)$, while in the third trimester mean BMI was $28.5( \pm 4.5)$.

Mean maternal weight gain in our study cohort was $11.2 \mathrm{~kg}( \pm 3.9)$. Compared to current guidelines only $40 \%$ of our pregnant women gained weight during gestation appropriately, $22 \%$ more than recommended and $38 \%$ less than recommended. Particularly underweight and overweight women did not follow gestational weight gain recommendations. In a multivariate model no association could be determined between GWG and maternal age, education, parity or fetal sex, whereas pre-pregnancy BMI $(p=0.003)$ was a significant predictor for the amount of weight gained during pregnancy

Within each BMI categories significant deviations from the recommendation were observed. According to maternal BMI at the beginning of pregnancy $86 \%$ of the underweight women gained less weight than suggested, whereas only $14 \%$ gained within the recommended range (Fig. 2). Of the normal weight participants every second woman (52\%) gained less than recommended, $38 \%$ appropriate and only a small minority (10\%) above the recommendation. The opposite distribution was noted in the overweight population: every second woman (50 \%) gained weight above the recommendation, $47 \%$ according to the recommendation, whereas in $3 \%$ gestational weight gain was insufficient. In obese women $50 \%$ gained above and $50 \%$ according to the recommendation.

In separate analyses total gestational weight gain correlated significantly with energy intake $(p=0.036)$. Per each $100 \mathrm{cal}$ increment maternal weight increased by $195 \mathrm{~g}$ (95 \% CI 13-378). A positive association was also found, when carbohydrate intake or consumption of monosaccharide and saccharose was taken into account. An increase of $1 \mathrm{~g}$ carbohydrate was related to an increment of $17 \mathrm{~g}$ in weight during pregnancy (95 \% CI 5-29;

percentage [\%]

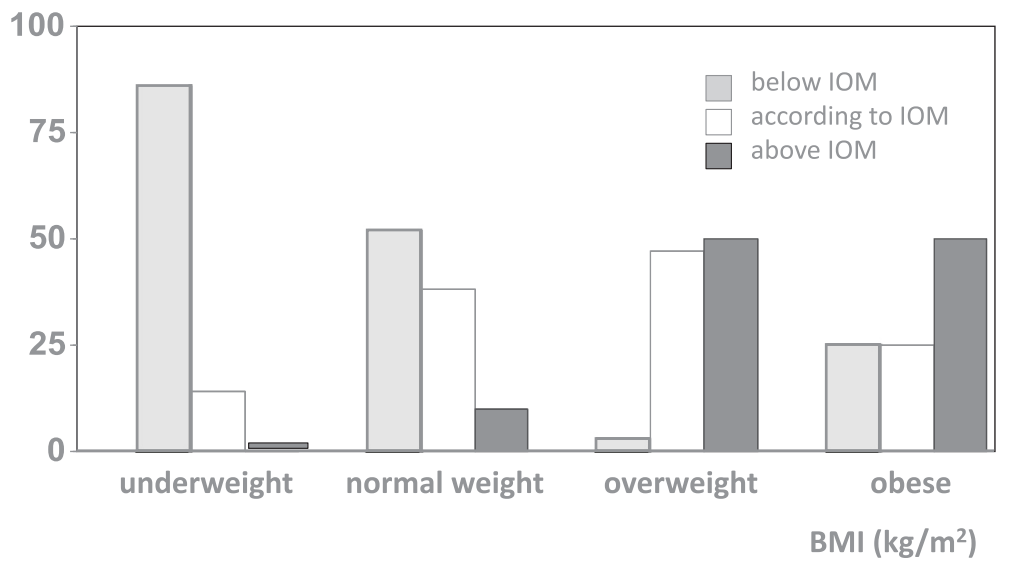

Fig. 2 Gestational weight gain according to the recommendation of the Institute of Medicine (IOM) (Institute of Medicine, 2009) [4] 
$p=0.008$ ), while $1 \mathrm{~g}$ sugar was associated with an increase of $26 \mathrm{~g}$ weight (95\% CI 8-44; $p=0.005)$. After further adjustment for energy intake, the correlation between sugar consumption and gestational weight gain remained significant $(p=0.049)$ whereas the association between carbohydrates and weight gain lost significance $(p=0.097)$. After adjustment for energy intake other macronutrients or fiber intake were not associated with gestational weight gain.

\section{Birth weight}

Two women terminated the pregnancy due to fetal malformations and one aborted spontaneously. Of the 197 births (birth weight was available in $n=196$ cases), mean birth weight was $3457 \mathrm{~g}( \pm 497), 24$ (12\%) of the children were characterized by a birth weight $>4000$ g. Newborn's weight was lower in normal weight mothers compared to overweight, obese and underweight mothers. In a multivariate analysis birth weight correlated significantly with maternal BMI at the beginning of pregnancy $(p=0.020)$, total weight gain $(p=0.020)$ and gestational week $(p<0.001)$ For each unit increment in pre-pregnancy BMI birth weight increased by $17 \mathrm{~g}$ (95\% CI 3-32), whereas each kilogram weight gained during pregnancy leads to an increase in birth weight by $20 \mathrm{~g}$ (95\% CI 3-36). An increase in birth weight by $138 \mathrm{~g}$ was observed per gestational week (95\% CI 89-187). All the other nutrients tested in this analysis were not associated significantly with birth weight.

\section{Discussion}

\section{Main Findings}

The aim of this analysis was to evaluate maternal weight gain as well as nutrient intake throughout each trimester of pregnancy compared to international recommendations and birth weight in a low risk population. Currently information as to weight development and dietary habits in pregnant women is limited.

A principal finding of our prospective birth cohort is that approximately two third of pregnant women did not comply regarding to gestational weight gain to current guidelines [4]. This has been previously described for other countries [26]. Every second woman with overweight or obesity and more than one third of the normal weight women gained more weight than recommended, whereas the majority of underweight women failed to gain sufficient weight. After adjustment for education, maternal age, baseline BMI and duration of the pregnancy a significant correlation between total weight gain and birth weight persisted

In addition a substantial proportion of women were characterized by poor dietary habits throughout the whole pregnancy although our population represents a rather educated (78\% higher education) and socioeconomically unrestricted population, which are factors associated with a better diet. As to macronutrients, more than every second women reported a fat consumption above the recommendation, characterized by a high intake of saturated fat, while the intake of polyunsaturated fatty acids, namely docosahexaenoic acid was insufficient. Compared to current guidelines the consumption of carbohydrates and fiber was mostly too low, and nearly half of the carbohydrates were obtained from sugar. Energy, as well as carbohydrate and sugar intake correlated significantly with total gestational weight gain even after adjustment for education and maternal age. The observed association between weight gain and monosaccharides and saccharose consumption remained significant even after further adjustment for energy intake.

With regard to micronutrient requirement a sustainable number of pregnant women fail to comply with the recommended daily intake. On the average none of the women reached the recommendation as to iron, folate and vitamin $\mathrm{D}$ and almost all participants reported an iodine intake below the guideline were independent from education levels or BMI categories.

\section{Strengths and Limitations}

To our knowledge our study is one of the first population-based ones evaluating not only gestational weight gain but also detailed dietary habits in a sample of German pregnant women. Data was collected prospectively, whereas most existing birth cohorts have recruited women in the course of pregnancy. Mean maternal age and rates of overweight and obesity are representative of the German population. Weight and nutrient intake was assessed in each trimester and compared to current recommendations.

However there are limitations that need to be addressed. First, our findings are confined to those women who voluntarily chose to take part in this study. Second, the sample is rather small and consisted of married women with a higher educational level. Third, we recorded maternal weight at the beginning of pregnancy in the first trimester. This did not differ significantly to recorded pre-pregnancy weight gain in our cohort (data not shown) and is widely used for these analysis as a true pre-pregnancy weight can only be obtained by patient recall. However we could draw the conclusion that in fact pregnancy weight gain could be even higher. Finally, nutrient assessment was obtained from only three $24 \mathrm{~h}$ recalls per women, one in each trimester. Further research is needed to confirm our results. In spite of these limitations, our data provides information as to weight gain and nutrient intake throughout pregnancy, findings that will have important implications for clinical practice. 


\section{Interpretation}

Mean maternal age in the PRINCE cohort is representative of the German population (mean maternal age at delivery of the first child is 30.2 years in Germany [27]. One third of the women were characterized by overweight or obesity, which is in line with findings from the German National Nutrition Survey II and the German DEGS-Study in women of childbearing age [1, 2]. Some studies reported, that maternal weight at the beginning of pregnancy seems to have a greater impact on health of mother and child than weight gained throughout pregnancy $[19,28]$. However, inadequate gestational weight gain, particularly excessive weight gain is known to be associated with unfavorable pregnancy outcomes $[7-9,11]$. In line with most previous research birth weight correlated significantly with maternal BMI at the beginning of pregnancy as well as with weight gain and gestational week even after further adjustment for education and age in a multivariate model. However most of the existing studies did not take into account gestational week. Excessive weight gain can be used as a potential predictor for offspring's overweight and obesity, particularly in normal weight women [3].

In addition, potential priming effects of high maternal weight gain on offsprings's overweight cannot be excluded [29]. Mean total gestational weight gain in our study was slightly below data reported from two other population-based birth cohorts [3]. Consistent with other studies two thirds of our cohort did not follow recommendations as to weight gain [3]. Weight development throughout pregnancy should also be discussed in the light of maternal post-partum weight retention, further pregnancies and lifelong cardiovascular risk for the mother. Women whose doctors recommended weight gains consistent with IOM guidelines were more likely to follow the recommendation [30]. Results from intervention studies indicate that nutrition and lifestyle counseling usually combined with supplementary weight monitoring in pregnant women reduced the rate of pregnancies with excessive gestational and weight retention at six months postpartum weight gain without increasing insufficient weight gain and seems to be safe [31-33].

Dietary habits before and throughout pregnancy influence short- and long-term health of mother and child over and beyond a potential influence on gestational weight gain. Particularly a low intake in critical micronutrients such as folate, iodine or iron leads to fetal complications. Maternal dietay habits may even play a role in terms of in utero programming of offspring appetite [34] and food preference of the offspring [35]. Up to now detailed information as to energy intake, macronutrients and micronutrient content of the diet at different stages of gestation are limited [36]. In our study population the mean energy intake increases significantly by
$8 \%$ during the course of pregnancy, which is in line with the recommended $10 \%$ [22]. However, the individual energy need may vary substantially depending mainly on the level of physical activity. Experience has shown, that most women decrease their physical activity throughout gestation, leading to the current recommendation that additional calories in overweight and obese women should be avoided [22].

More than one out of ten women did not reach the recommended protein intake in our study, while every second women was above the recommended fat intake throughout pregnancy. Data from animal studies indicate that high fat maternal diets during pregnancy seems to have adverse effects in offspring with regard to exercise performance, hepatic lipid accumulation, insulin resistance, and development of atherosclerosis [37-39]. As to carbohydrate and fiber intake the majority of women were obviously below the recommendation.

Present findings reflect in most parts mean dietary intake of macronutrients and fiber in the women of childbearing age in the German population, leading to the assumption, that without targeted intervention "healthy" pregnant women will not change the quality of their diet [1]. Initiatives to promote a healthy lifestyle during pregnancy like the German 'Healthy Start - Young Family Network' are helpful to increase awareness, however, more individual advice is highly recommended [19]. A mismatch between dietary practice and macronutrient recommendation in pregnant women is supported by a systematic review and meta-analysis including data of developed countries [23]. The quality of fat and carbohydrate intake is also of increasing interest. In our study saturated fat contributed largely to the fat consumption, while the intake of polyunsaturated fatty acids, namely docosahexaenic acid was too low. These findings are in line with findings from other European countries [23]. Carbohydrate intake, particularly sugar seems to be an important determinate of gestational weight gain in our cohort, which is supported by data from a Danish birth cohort, analyzing the impact of added sugar on excessive weight development during pregnancy [40].

To supply adequate amounts of vitamins, minerals and other micronutrients a nutrient-dense diet is desirable, particularly in the light of an increase in the requirement of certain micronutrients. Consistent with a meta-analysis in developed countries, our findings indicate that pregnant women are at risk of suboptimal micronutrient intake [24]. On the average none of the women met the recommendation as to folate, iron, and vitamin $\mathrm{D}$ throughout pregnancy and almost all were below the recommendation as to iodine intake. These findings reflect in most parts mean dietary intake of vitamins and minerals in women of childbearing age in the German population. The reference values for folate, iron, 
iodine and vitamin $\mathrm{D}$ can hardly be reached through diet alone [1, 22]. Supplying micronutrients to protect deficiencies can be useful to reduce adverse outcomes, but should not replace a healthy well-balanced diet. In addition, further studies to evaluate the effect of various combination and doses of micronutrients are warranted [41].

\section{Conclusions}

In summary, our analysis contributes to the limited literature on nutrient intake and weight gain throughout pregnancy. The data clearly indicate that the majority of women do not follow current recommendations as to dietary habits and gestational weight gain. Increasing rates of obese women of childbearing age will strengthen the problem. In the light of the present study a lifestyle counseling delivered to all pregnant women is highly justified, as intervention during pregnancy are characterized by a unique treatment adherence and can prevent short-term and long-term health risk of mother and child. Dietary advice is part of the prenatal care in Germany. However, this is mostly done by gynecologists and not by nutritional experts. Often this information is given as a leaflet to the patients. This highlights the need of high quality nutritional brochures but also individual advice affect the metabolic and weight trajectory both for women and their offspring.

\section{Abbreviations}

BMI, body-mass-index; D-A-CH, Germany-Austria-Switzerland; DHA, docosahexaenoic acid; GWG, gestational weight gain; IOM, US Institute of Medicine; IUGR, intra-uterine growth restriction; SAFA, Saturated fatty acids; SPSS, Statistical Package for the Social Sciences

\section{Acknowledgement}

We are indebted to all participants of the PRINCE study for their collaboration.

\section{Funding}

Financial support of the PRINCE study was primarily given by LEXI (Landes-Exzellenz-Initiative), State of Hamburg and the DFG (german research association, KFO 296, Grant-Number: DI 2103/2-1 AOBJ: 619132).

\section{Availability of data and materials}

Raw data will be made available upon reasonable request to the corresponding author.

\section{Authors' contributions}

A.D. conceived, designed and performed the experiments, analyzed the data and wrote the paper. S.L. contributed analyzing tools, analyzed the data and wrote the paper. M.P. and G.H. performed the experiments. A.Dr. analyzed the data. K.H. contributed materials and tools and designed the study. P.A. and B.Z. conceived and designed the experiment, analyzed the data and wrote the paper and contributed equally. All authors read and approved the final manuscript.

\section{Competing interests}

BZ reports fees from Bayer for lectures and a review article.

\section{Consent for publication}

Not applicable.

\section{Ethics approval and consent to participate}

The study protocol was approved by the Ethics committee of the Hamburg State Board of Physicians (06.91.2011, PV3694) and conducted according to the principles of the Declaration of Helsinki. Written informed consent was obtained from all participants.

\section{Author details}

${ }^{1}$ Department of Obstetrics and Fetal Medicine, University Medical Center Hamburg-Eppendorf, Martinistrasse 52, Hamburg 20246, Germany. ${ }^{2}$ Institute for Medical Biometry and Epidemiology, University Medical Center Hamburg-Eppendorf, Hamburg 20246, Germany. ${ }^{3}$ Preventive Medicine, University Heart Center, University Medical Center Hamburg-Eppendorf, Hamburg, Hamburg.

Received: 18 March 2016 Accepted: 4 August 2016

Published online: 15 August 2016

\section{References}

1. Max Rubner Institut. Nationale Verzehrstudie II, Ergebnisbericht, Teil 1. Karlsruhe: Bundesforschungsinstitut für Ernährung und Lebensmittel; 2008

2. Mensink GBM, Schinekiewitz $M$, Haftenberger M, Lampert T, Ziese T, Scheidt-Nave C. Übergewicht und Adipositas in Deutschland. Ergebnisse der Studie zur Gesundheit Erwachsener in Deutschland (DEGS1). Bundesgesundheitsblatt. 2013 Nov 24;56:786-94

3. Beyerlein A, Nehring I, Rzehak P, Heinrich J, Müller MJ, Plachta-Danielzik S, et al. Gestational weight gain and body mass index in children: results from three german cohort studies. PLoS ONE. 2012;7(3):e33205.

4. Institute of Medicine (US), National Research Council (US) Committee to Reexamine IOM Pregnancy Weight Guidelines, Rasmussen KM, Yaktine AL. Weight Gain During Pregnancy: Reexamining the Guidelines. Washington (DC): National Academies Press (US); 2009.

5. Gaillard R. Maternal obesity during pregnancy and cardiovascular development and disease in the offspring. Eur J Epidemiol. 2015 Sep 16

6. Leddy MA, Power ML, Schulkin J. The impact of maternal obesity on maternal and fetal health. Rev Obstet Gynecol. 2008;1(4):170-8.

7. Heslehurst N, Simpson H, Ells LJ, Rankin J, Wilkinson J, Lang R, et al. The impact of maternal BMI status on pregnancy outcomes with immediate short-term obstetric resource implications: a meta-analysis. Obes Rev. 2008; 9(6):635-83.

8. Guelinckx I, Devlieger R, Bogaerts A, Pauwels S, Vansant G. The effect of prepregnancy BMI on intention, initiation and duration of breast-feeding. Public Health Nutr. 2012;15(5):840-8.

9. Sarwer DB, Allison KC, Gibbons LM, Markowitz JT, Nelson DB. Pregnancy and obesity: a review and agenda for future research. J Womens Health (Larchmt). 2006;15(6):720-33.

10. Mosca L, Benjamin EJ, Berra K, Bezanson JL, Dolor RJ, Lloyd-Jones DM, et al. Effectiveness-based guidelines for the prevention of cardiovascular disease in women-2011 update: a guideline from the american heart association. Circulation. 2011;123:1243-62.

11. McClure CK, Catov JM, Ness R, Bodnar LM. Associations between gestational weight gain and BMI, abdominal adiposity, and traditional measures of cardiometabolic risk in mothers 8 y postpartum. Am J Clin Nutr. 2013;98(5): $1218-25$.

12. Flenady V, Koopmans L, Middleton P, Frøen JF, Smith GC, Gibbons K, et al, Major risk factors for stillbirth in high-income countries: a systematic review and meta-analysis. Lancet. 2011;377(9774):1331-40.

13. Barker DJP. Mothers, babies and disease in later life. 2nd edition. Churchill Livingstone: 1998. ISBN-10: 0443061653

14. Catalano PM, Mclntyre HD, Cruickshank JK, McCance DR, Dyer AR, Metzger $\mathrm{BE}$, et al. The hyperglycemia and adverse pregnancy outcome study: associations of GDM and obesity with pregnancy outcomes. Diabetes Care. 2012:35(4):780-6.

15. Schellong K, Schulz S, Harder T, Plagemann A. Birth weight and long-term overweight risk: systematic review and a meta-analysis including 643,902 persons from 66 studies and 26 countries globally. PLoS ONE. 2012;7(10): e47776.

16. Reynolds RM, Allan KM, Raja EA, Bhattacharya S, McNeill G, Hannaford PC, et al. Maternal obesity during pregnancy and premature mortality from cardiovascular event in adult offspring: follow-up of 1323275 person years. BMJ. 2012;347:44539-9.

17. Slyvka $Y$, Zhang $Y$, Nowak FV. Epigenetic effects of paternal diet on offspring: emphasis on obesity. Endocrine. 2015;48(1):36-46. 
18. Symonds ME, Mendez MA, Meltzer HM, Koletzko B, Godfrey K, Forsyth S, et al. Early life nutritional programming of obesity: mother-child cohort studies. Ann Nutr Metab. 2012;62(2):137-45.

19. Koletzko B, Bauer CP, Bung P, Cremer M, Flothkötter M, Hellmers C, et al. German national consensus recommendations on nutrition and lifestyle in pregnancy by the 'Healthy Start - Young Family Network'. Ann Nutr Metab. 2012;63(4):311-22

20. Smith CJ, Ryckman KK. Epigenetic and developmental influences on the risk of obesity, diabetes, and metabolic syndrome. Diabetes Metab Syndr Obes. 2014;8:295-302.

21. Max Rubner Institu. Nationale Verzehrstudie II, Ergebnisbericht, Teil 2. Karlsruhe: Bundesforschungsinstitut für Ernährung und Lebensmitte; 2008.

22. D-A-CH Referenzwerte für die Nährstoffzufuhr. Deutsche Gesellschaft für Ernährung (DGE), Österreichische Gesellschaft für Ernährung (ÖGE), Schweizerische Vereinigung für Ernährung (SGE). Umschau/Braus, Frankfurt/ Main 2015, ISBN-10: 3829571143

23. Blumfield ML, Hure AJ, Macdonald-Wicks L, Smith R, Collins CE. Systematic review and meta-analysis of energy and macronutrient intakes during pregnancy in developed countries. Nutr Rev. 2012;70(6):322-36.

24. Blumfield ML, Hure AJ, Macdonald-Wicks L, Smith R, Collins CE. A systematic review and meta-analysis of micronutrient intakes during pregnancy in developed countries. Nutr Rev. 2013;71(2):118-32.

25. Kleinwechter H, Schaefer-Graf U. Gestationsdiabetes-praktische Aspekte nach der neuen S3-Leitlinie. Diabetologie und Stoffwechsel. Diabetologie und Stoffwechsel. 2011;24(3):27-40.

26. Rasmussen KM, Catalano PM, Yaktine AL. New guidelines for weight gain during pregnancy: what obstetrician/gynecologists should know. Curr Opin Obstet Gynecol. 2009;21(6):521-6.

27. Statistisches Bundesamt (2012), Fachserie 1, Reihe 1.1 - 2010, www.destatis.de

28. National Institute for Health and Clinical Excellence. Dietary Interventions and Physical Activity Interventions for Weight Management before, during and after Pregnancy. London: National Institute for Health and Clinical Excellence; 2010

29. Fraser A, Tilling K, Macdonald-Wallis C, Sattar N, Brion M-J, Benfield L, et al. Association of maternal weight gain in pregnancy with offspring obesity and metabolic and vascular traits in childhood. Circulation. 2010;121(23):2557-64.

30. Tovar A, Guthrie LB, Platek D, Stuebe A, Herring SJ, Oken E. Modifiable predictors associated with having a gestational weight gain goal. Matern Child Health J. 2011;15(7):1119-26.

31. Tanentsapf I, Heitmann BL, Adegboye ARA. Systematic review of clinical trials on dietary interventions to prevent excessive weight gain during pregnancy among normal weight, overweight and obese women. BMC Pregnancy Childbirth. 2011;11:81.

32. Streuling I, Beyerlein A, von Kries R. Can gestational weight gain be modified by increasing physical activity and diet counseling? A metaanalysis of interventional trials. Am J Clin Nutr. 2010;92(4):678-87.

33. Rauh K, Gabriel E, Kerschbaum E, Schuster T, Kries Von R, Amann-Gassner U, et al. Safety and efficacy of a lifestyle intervention for pregnant women to prevent excessive maternal weight gain: a cluster-randomized controlled trial. BMC Pregnancy Childbirth. 2013;13:151

34. Brion M-JA, Ness AR, Rogers I, Emmett P, Cribb V, Davey-Smith G, et al. Maternal macronutrient and energy intakes in pregnancy and offspring intake at $10 \mathrm{y}$ : exploring parental comparisons and prenatal effects. Am J Clin Nutr. 2010;91(3):748-56.

35. Gugusheff JR, Ong ZY, Muhlhausler BS. The early origins of food preferences: targeting the critical windows of development. FASEB J. 2015;29(2):365-73.

36. Talai Rad N, Ritterath C, Siegmund T, Wascher C, Siebert G, Henrich W, et al. Longitudinal analysis of changes in energy intake and macronutrient composition during pregnancy and 6 weeks post-partum. Arch Gynecol Obstet. 2011;283(2):185-90.

37. Wakana N, Irie D, Kikai M, Terada K, Yamamoto K, Kawahito H, et al. Maternal high-fat diet exaggerates atherosclerosis in adult offspring by augmenting periaortic adipose tissue-specific proinflammatory response. Arterioscler Thromb Vasc Biol. 2015;35(3):558-69.

38. Benatti RO, Melo AM, Borges FO, Ignacio-Souza LM, Simino LAP, Milanski M, et al. Maternal high-fat diet consumption modulates hepatic lipid metabolism and microRNA-122 (miR-122) and microRNA-370 (miR-370) expression. Br J Nutr. 2014;111(12):2112-22.

39. Walter I, Klaus S. Maternal high-fat diet consumption impairs exercise performance in offspring. J Nutr Sci. 2014;3:e61.
40. Maslova E, Halldorsson Tl, Astrup A, Olsen SF. Dietary protein-to-carbohydrate ratio and added sugar as determinants of excessive gestational weight gain: a prospective cohort study. BMJ Open. 2015;5(2):e005839.

41. Zerfu TA, Ayele HT. Micronutrients and pregnancy; effect of supplementation on pregnancy and pregnancy outcomes: a systematic review. Nutr J. 2013;12:20.

\section{Submit your next manuscript to BioMed Central and we will help you at every step:}

- We accept pre-submission inquiries

- Our selector tool helps you to find the most relevant journal

- We provide round the clock customer support

- Convenient online submission

- Thorough peer review

- Inclusion in PubMed and all major indexing services

- Maximum visibility for your research

Submit your manuscript at www.biomedcentral.com/submit 